\title{
Визначення кореляційної залежності засвоєння базових елементів художньої гімнастики від використання класичного екзерсису дівчаток 5-6 років
}

\author{
Ольга Рябченко' \\ Ельміра Алієва Ельхан кизи²
}

Харківська державна академія фізичної культури ${ }^{1}$, Харків, Україна

Sports complex Ruslan 93 Sport Club "GymKids" 2, Баку, Азербайджан

Мета: встановити кореляційний взаємозв'язок базових елементів художньої гімнастики та спеціальних вправ класичного екзерсису.

Матеріал і методи: дослідження проводилося на базі КЗ «КДЮСШ №1 ХМР» серед дівчаток 5-6 років, які займаються художньою гімнастикою. В експерименті брали участь 60 юних спортсменок. Для встановлювання кореляційної залежності було залучено 3 хореографа і 4 тренера з художньої гімнастики. В зв'язку з тим, що дослідження проводилося в групах початкової підготовки другого року навчання, була застосована 10-ти бальна шкала оцінки. На початку дослідження визначався вплив класичного екзерсису на засвоєння базових елементів художньоі гімнастики. Наприкінці - встановлювалася кореляція між елементами художньої гімнастики та спеціальними вправами класичного екзерсису.

Результати: в процесі застосування спеціальних вправ класичного екзерсису (фр. ехеrcice - «вправа»), тобто вивчення елементарних базових рухів біля станку - підвищився рівень виконання базових елементів художньої гімнастики, таких як: стрибок «козак» $(t=2,12 ; p<0,05)$, рівновага «вперед» $(t=3,57 ; p<0,001)$, рівновага «атитюд» $(t=2,68 ; p<0,01)$, поворот «пасе» $(t=2,21 ; p<0,05)$, «колесо» $(t=1,72 ; p>0,05)$.

Висновки: у результаті досліджень визначено кореляційний взаємозв'язок базових елементів художньої гімнастики зі спеціальними вправами класичного екзерсису.

\section{Ключові слова: художня гімнастика, базові елементи, класичний екзерсис, кореляція.}

\section{Вступ}

Сучасні види та течії хореографії стають надзвичайно популярними серед дітей та молоді [5]. Особливо актуальним питанням є руховий і фізичний розвиток дівчаток 5-6 років, що займаються художньою гімнастикою. У зв'язку з цим виникає потреба у формуванні основ культури рухів у тренувальному процесі юних спортсменок.

Формування основ культури руху у дітей 3-6-річного віку, в силу їх схильності за своєю сприйнятливістю до різної структури рухової діяльності з її якісної та кількісної характеристики, природно вважає встановлення структури особливостей соматотипів розглянутого контингенту та встановлення всіх його «маргінальних» груп. В цьому разі культуру руху буде визначати доступна для цього віку техніка засвоєних рухів [11].

На сьогодні в світі художньої гімнастики відбулися зміни правил суддівства на наступний олімпійський цикл (2022-2024). За основними вимогами в індивідуальних вправах гімнастка повинна виконувати лише елементи, які вона може виконати безпечно та з високим ступенем естетичної та технічної підготовленості. Дуже погано виконані елементи не будуть оцінені Суддями Труднощі (D) та будуть покарані зменшенням Суддів Виконання (E) [10].

Таким чином, для кращого засвоєння базових елементів художньої гімнастики потрібно приділити осо- бливе значення навчанню спеціальним вправам класичного екзерсису дівчаток 5-6 років.

На думку І. О. Єльцова, екзерсис класичного танцю - ідеальна й універсальна система вправ і комбінацій, створена в процесі тривалого хореографічного досвіду, елементи якої, пройшовши природний відбір, увійшли до складу екзерсису, як, дійсно, необхідні вправи, які розвивають і тренують. В екзерсисі всебічно розвиваються м'язи ніг, тулуб, руки і голова, покращується координація рухів.

У зв'язку з цим пошук найбільш ефективних засобів хореографії для підготовки юних спортсменок з художньої гімнастики набуває особливої актуальності.

Мета дослідження - встановити кореляційний взаємозв'язок базових елементів художньої гімнастики та спеціальних вправ класичного екзерсису.

\section{Матеріал і методи дослідження}

У роботі було використано наступні методи дослідження: теоретичний аналіз і узагальнення науково-методичної літератури, педагогічне спостереження, педагогічний експеримент та методи математичної статистики.

Дослідження проводилося на базі КЗ «КДЮСШ №1 XMP» серед дівчаток 5-6 років, які займаються художньою гімнастикою. В експерименті брали участь 60 юних 


\section{СЛОБОЖАНСЬКИЙ НАУКОВО-СПОРТИВНИЙ ВІСНИК}

спортсменок, батьки яких дали згоду на їх участь. Для встановлювання кореляційної залежності було залучено 3 хореографа і 4 тренера з художньої гімнастики. В зв'язку з тим, що дослідження проводилося в групах початкової підготовки другого року навчання, була застосована 10ти бальна шкала оцінки. На початку дослідження визначався вплив класичного екзерсису на засвоєння базових елементів художньої гімнастики. Наприкінці - встановлювалася кореляція між елементами художньої гімнастики та спеціальними вправами класичного екзерсису.

Зв'язок дослідження з науковими чи практичними завданнями, планами, програмами. Наукова робота виконана відповідно до ініціативної теми НДР кафедри гімнастики, танцювальних видів спорту та хореографії ХДАФК: «Теоретико-методологічні основи розвитку системо-утворюючих компонентів фізичної культури (спорт, фітнес і рекреація) на 2020-2025 рр., (номер державної реєстрації 0120U01215).

\section{Результати дослідження}

Дослідження, яке проводилось два місяці, мало за мету визначити вплив вправ класичного екзерсису на засвоєння базових елементів художньої гімнастики. Для цього були проведені попередні та кінцеві оцінювання виконання як самих елементів художньої гімнастики, так і вправ класичного екзерсису.

Отримані результати та проведений на їх основі аналіз, який представлено у таблиці 1, свідчать про певний вибір спеціальних вправ класичного екзерсису для засвоєння базових елементів художньої гімнастики. Найбільш суттєвий вплив ( $t=3,57 ; p<0,001)$ від використання цих вправ було отримано при виконанні такого елемен-

Таблиця 1

Статистичні показники впливу спеціальних вправ на засвоєння базових елементів художньої гімнастики $(n=60)$, бали

\begin{tabular}{|c|c|c|c|c|c|}
\hline \multirow[b]{2}{*}{$\begin{array}{c}\text { Елемент } \\
\text { художньої } \\
\text { гімнастики }\end{array}$} & \multirow[b]{2}{*}{$\begin{array}{c}\text { Спеціальні вправи } \\
\text { класичного екзерсису }\end{array}$} & \multicolumn{2}{|c|}{ Оцінки } & \multirow[b]{2}{*}{$t_{e}$} & \multirow[b]{2}{*}{$p$} \\
\hline & & $\begin{array}{c}\text { попередні } \\
\bar{X} \pm m, \\
\text { бали }\end{array}$ & $\begin{array}{c}\text { кінцеві } \\
\bar{X} \pm m, \\
\text { бали }\end{array}$ & & \\
\hline $\begin{array}{l}\text { Стрибок } \\
\text { «козак» }\end{array}$ & $\begin{array}{l}\text { Relevé } \\
\text { Demi-plié } \\
\text { Grand battement } \\
\text { Sauté } \\
\text { Assemble }\end{array}$ & $5,98 \pm 0,19$ & $6,63 \pm 0,24$ & 2,12 & $<0,05$ \\
\hline $\begin{array}{l}\text { Рівновага } \\
\text { «вперед» }\end{array}$ & $\begin{array}{l}\text { Позиції рук (I, III, II) } \\
\text { Позиції ніг (VI, I, III, V) } \\
\text { Battement tendu } \\
\text { Battement tendu jete } \\
\text { Grand battement jete } \\
\text { Adajio }\end{array}$ & $5,63 \pm 0,20$ & $6,80 \pm 0,26$ & 3,57 & $<0,001$ \\
\hline $\begin{array}{l}\text { Рівновага } \\
\text { «атитюд» }\end{array}$ & $\begin{array}{l}\text { Позиції рук (I, III, II) } \\
\text { Позиції ніг (VI, I, III, V) } \\
\text { Battement tendu } \\
\text { Battement fondu } \\
\text { Grand battement jete } \\
\text { Relevé }\end{array}$ & $5,68 \pm 0,18$ & $6,55 \pm 0,27$ & 2,68 & $<0,01$ \\
\hline $\begin{array}{l}\text { Поворот } \\
\text { «пасе» }\end{array}$ & $\begin{array}{l}\text { Позиції рук (I, III, II) } \\
\text { Позиції ніг (I, IV, VI) } \\
\text { I, II, III port de bras } \\
\text { Апломб } \\
\text { Утримання положення } \\
\text { однієї ноги в «пасе» } \\
\text { Утримання положення } \\
\text { однієї ноги в «пасе»на } \\
\text { relevé }\end{array}$ & $5,95 \pm 0,18$ & $6,63 \pm 0,25$ & 2,21 & $<0,05$ \\
\hline «Колесо» & $\begin{array}{l}\text { Рухові дії біля станку } \\
\text { Adajio } \\
\text { Grand battement jete } \\
\text { Утримання рук (II, III } \\
\text { позиціiі) }\end{array}$ & $5,75 \pm 0,16$ & $6,22 \pm 0,22$ & 1,72 & $>0,05$ \\
\hline
\end{tabular}


ту як рівновага «вперед». Це свідчить про те, що набір тренувальних вправ, який був залучений, посприяв розвитку сили м'язів плечового поясу та м'язів ніг, еластичності зв'язок та стійкості у дівчат.

У меншій мірі, але покращилися результати виконання елементів: рівновага «атитюд» $(\mathrm{t}=2,68 ; \mathrm{p}<0,01)$, поворот «пасе» $(\mathrm{t}=2,21 ; \mathrm{p}<0,05)$ та стрибок «козак» $(\mathrm{t}=2,12$; $p<0,05)$. Це обумовлено тим, що в період тренувального процесу юні спортсменки не достатньо засвоїли базові рухи, яким навчалися біля станку.

Слід зауважити, що використані вправи за своєю статикою та динамікою максимально наближені до базових елементів художньої гімнастики, що досліджуються. Отже, дівчатам 5-6 років легше освоювали навчальну програму з художньої гімнастики завдяки подібним вправам класичного танцю. Проте виконання такого елементу як «колесо» $(t=1,72 ; p>0,05)$ не зазнало суттєвого впливу від використання спеціальних вправ, що потребує їх корегування та подальшого застосування. Для виявлення ефективності використання спеціальних вправ класичного екзерсису на засвоєння базових елементів художньої гімнастики було проведено кореляційний аналіз.

За даними отриманих результатів вправи, що використовуються при засвоєнні такого елементу, як стрибок «козак», мають позитивний ефект, так як коефіцієнт кореляції $€$ на рівні середнього $(r=0,51-0,60)$. Складовою частиною зазначеного елементу $€$ спеціальна вправа «grand battement» ( $r=60)$, «великий кидок, помах» на 90 і вище витягнутої ноги в потрібний напрямок. Ця вправа розвиває силу ніг, різкість руху ніг, крок [9] (табл. 2).

Виконання елементу рівновага «вперед» включає різні технічні компоненти: підняття ноги на 90, утримання пози на «releve», зміна положення тіла і позиції рук, тому найбільш ефективною є спеціальна вправа «adajio» $(r=0,63)$ та «grand battement jete» (табл. 3). Також для виконання рівноваги не менш важливою $є$ вправа для тренування позиції рук $(r=0,49)$, що стабілізує положення тіла у просторі.

Вправи, що застосовувалися для виконання базового елементу художньої гімнастики - рівновага «атитюд», передбачають специфіку формування рухів у танцювальному спорті. Особливу увагу треба звернути під час навчання юних спортсменок елементарним рухам класичного танцю за виворітними позиціями ніг, положенням тіла та утриманням вільної ноги. Всі вище перелічені вправи (табл. 4) мають велике значення для створення окремих складових базового елементу, особливо «grand battement jete» $(r=0,68)$ та «battement fondu» $(r=0,58)$.

Як свідчать результати оцінювання базового елементу поворот «пасе», найбільш ефективною є спеціальна вправа «утримання положення однієї ноги в «пасе» на relevй» $(r=0,70)$ (табл. 5). Застосування цієї вправи впливає на роботу м'язів ніг і рук, об'єднує рухи тілом в одне ціле. Групи м'язів, що фіксують тулуб і спину в ділянці попереку, дозволяють утриматися в строго вертикальному положенні та нерухомо.

Таким чином, спеціальна вправа «утримання положення однієї ноги в «пасе» на relevй», виробляє стійкість корпусу, що не збиває з наміченого напрямку і придає естетичності виконання елементу.

Під час виконання базового елементу «колесо» з'ясувалося, що виконання «рухової дії біля станку» значно вплинуло $(r=0,57)$ на навчання цієї рухової дії (табл. 6). Менший показник $(r=0,48)$ виявлено у вправі «grand battement jete», це свідчить про те, що певну вправу треба виконувати послідовно з підвищенням рівня координації всього тіла.

Таблиця 2

Матриця кореляційної залежності спеціальних вправ класичного екзерсису та виконання базового елементу художньої гімнастики стрибок «козак»

\begin{tabular}{|c|l|c|}
\hline $\begin{array}{c}\text { № } \\
\Pi / \Pi\end{array}$ & \multicolumn{1}{|c|}{ Спеціальні вправи класичного екзерсису } & Коефіцієнт кореляції \\
\hline 1 & Relevé & 0,34 \\
\hline 2 & Demi-plié & 0,43 \\
\hline 3 & Grand battement & 0,60 \\
\hline 4 & Sauté & 0,53 \\
\hline 5 & Assemble & 0,51 \\
\hline
\end{tabular}

Таблиця 3

Матриця кореляційної залежності спеціальних вправ класичного екзерсису та виконання базового елементу художньої гімнастики - рівновага “вперед»

\begin{tabular}{|c|l|c|}
\hline $\begin{array}{c}\text { № } \\
\Pi / \Pi\end{array}$ & \multicolumn{1}{|c|}{ Спеціальні вправи класичного екзерсису } & Коефіцієнт кореляції \\
\hline 1 & Позиції рук (I, III, II) & 0,49 \\
\hline 2 & Позиції ніг (VI, I, III, V) & 0,32 \\
\hline 3 & Battement tendu & 0,36 \\
\hline 4 & Battement tendu jete & 0,42 \\
\hline 5 & Grand battement jete & 0,57 \\
\hline 6 & Adajio & 0,63 \\
\hline
\end{tabular}


Таблиця 4

Матриця кореляційної залежності спеціальних вправ класичного екзерсису та виконання базового елементу художньої гімнастики - рівновага «атитюд»

\begin{tabular}{|c|l|c|}
\hline $\begin{array}{c}\text { № } \\
\text { п/п }\end{array}$ & \multicolumn{1}{|c|}{ Спеціальні вправи класичного екзерсису } & Коефіцієнт кореляції \\
\hline 1 & Позиції рук (I, III, II) & 0,44 \\
\hline 2 & Позиції ніг (VI, I, III, V) & 0,39 \\
\hline 3 & Battement tendu & 0,31 \\
\hline 4 & Battement fondu & 0,58 \\
\hline 5 & Grand battement jete & 0,68 \\
\hline 6 & Relevé & 0,47 \\
\hline
\end{tabular}

Таблиця 5

Матриця кореляційної залежності спеціальних вправ класичного екзерсису та виконання базового елементу художньої гімнастики - поворот «пасе»

\begin{tabular}{|c|l|c|}
\hline $\begin{array}{c}\text { № } \\
\text { п/п }\end{array}$ & \multicolumn{1}{|c|}{ Спеціальні вправи класичного екзерсису } & Коефіцієнт кореляції \\
\hline 1 & Позиції рук (I, III, II) & 0,47 \\
\hline 2 & Позиції ніг (I, IV, VI) & 0,33 \\
\hline 3 & I, II, III port de bras & 0,29 \\
\hline 4 & Апломб & 0,51 \\
\hline 5 & Утримання положення однієї ноги в «пасе» & 0,59 \\
\hline 6 & Утримання положення однієї ноги в «пасе» на relevé & 0,70 \\
\hline
\end{tabular}

Таблиця 6

Матриця кореляційної залежності спеціальних вправ класичного екзерсису та виконання базового елементу художньої гімнастики «колесо»

\begin{tabular}{|c|l|c|}
\hline $\begin{array}{c}\text { № } \\
\text { 그 }\end{array}$ & \multicolumn{1}{|c|}{ Спеціальні вправи класичного екзерсису } & Коефіцієнт кореляції \\
\hline 1 & Рухові дії біля станку & 0,57 \\
\hline 2 & Adajio & 0,41 \\
\hline 3 & Grand battement jete & 0,48 \\
\hline 4 & Утримання рук (II, III позиції) & 0,37 \\
\hline
\end{tabular}

\section{Висновки / Дискусія}

Отримані результати дослідження дають привід зробити висновок, що застосування спеціальних вправ класичного екзерсису дозволили підвищити рівень виконання таких базових елементів художньої гімнастики як рівновага «вперед» ( $t=3,57 ; p<0,001)$ оцінка підвищилась на 21\%; рівновага «атитюд» $(t=2,68 ; p<0,01)$ результати поліпшились на 15\%; поворот «пасе» $(\mathrm{t}=2,21$; $\mathrm{p}<0,05)$ оцінка покращилась на $11 \%$ та стрибок «козак» $(t=2,12 ; p<0,05)$ - на $11 \%$.

Використання спеціальних вправ класичного екзерсису, як і передбачалось, посприяло формуванню рухових якостей дівчат 5-6 років, що спрямовані на ефективність виконання базових елементів художньої гімнастики.

За результатами оцінювання встановлено кореляційну залежність виконання базових елементів художньої гімнастики та спеціальних вправ класичного танцю, що забезпечують виконання елементів: стрибок «козак» має середній рівень кореляції зі спеціальними вправами: «grand battement» $(r=0,60)$, «sautদ̆» $(r=0,53)$ та «assemble» $(r=0,51)$; рівновага «вперед» 3 «adajio» $(r=0,63)$ та «grand battement jete» $(r=0,57)$; рівновага «атитюд» зі спеціальною вправою «grand battement jete», яка має високий рівень кореляції $(r=0,68)$ та «battement fondu» $(r=0,58)$; поворот «пасе» зі спеціальною вправою «утримання положення однієї ноги в «пасе» на relevй», яка має високий рівень кореляції $(r=0,70)$ та «утримання положення однієї ноги в «пасе»» $(r=0,59)$, «апломб» $(r=0,51)$; «колесо» 3 «рухові дії біля станку» $(r=0,57)$.

Проведені дослідження підтверджують дані кореляційного взаємозв'язку базових елементів художньої гімнастики та спеціальних вправ класичного екзерсису, що дають можливість використовувати їх в тренувальному процесі юних гімнасток.

Перспектива подальших досліджень полягає у корегуванні та подальшому застосуванні додаткових вправ класичного екзерсису для поліпшення засвоєння базових елементів художньої гімнастики юними спортсменками. 
Конфлікт інтересів. Автори заявляють, що немає конфлікту інтересів, який може сприйматися як такий, що може завдати шкоди неупередженості статті.

Джерела фінансування. Ця стаття не отримала фінансової підтримки від державної, громадської або комерційної організації.

\title{
Список посилань
}

1. Артем'єва Г. П., Мошенська Т. В. (2018), «Роль і значення хореографії у гімнастичних і танцювальних видах спорту», Слобожанський науково-спортивний вісник, № 4(66). С. 32-36. doi:10.15391/snsv.4.005

2. Базарова Н. П., Мей В. П. (2006), Азбука классического танца. Первые три года обучения: учебное пособие, 3-е изд., Издательство «Лань», 240 с.

3. Батєєва Н. П., Кізим П. М., Тіткова І. О., Луценко Л. С. (2014), «Використання засобів класичного танцю для вдосконалення техніки виконання поворотів юними гімнастками», Слобожанський науково-спортивний вісник, № 3(41). C. 19-22. dx.doi. org/10.15391/snsv.3.003

4. Бондаренко Т. М. (2014), Виховання гармонійної особистості засобами художньої гімнастики: монографія; за заг. ред. В. М. Клочка; Харк. нац. ун-т міськ. госп-ва ім. О. М. Бекетова, Х.: ХНУМГ, 270 с.

5. Борсук Н. В., Мосякова І. Ю., Окушко Т. К. (2011), Спортивна сучасна хореографія: комплексна навчальна програма 3 позашкільної освіти, К., 64 с.

6. Гальченко Л. В., Бессарабова О. В., Пісарькова О. Р. (2017), «До питання організації тренувального процесу на початковому етапі підготовки дівчат у художній гімнастиці», Вісник Запорізького національного університету: збірник наукових статей. Фізичне виховання та спорт, Запорізький національний університет. Запоріжжя, С. 196-204.

7. Голдрич О. С. (2006), Хореографія: посібник з основ хореографічного мистецтва та композиції танцю. Вид. друге, доповнене. Львів: СПОлОМ, 172 с.

8. Рябченко О. В. (2021), «Застосування елементів хореографії в тренувальному процесі спортсменок-початківців для успішного освоєння програм з художньої гімнастики», Слобожанський науково-спортивний вісник, № 3(83). С. 88-94. doi:10.15391/ snsv. 3.013

9. Соболь В. А., Панова Е. В. (2019), Классический танец: теория и методика преподавательской деятельности: методическое пособие. Тюмень, 64 с.

10. Правила судейства по художественной гимнастике 2022-2024 г. (2021), Исполнительный Комитет ФИж, Международная федерация гимнастики, 241 с.

11. Riabchenko O. V. (2015), "The formation of bases of culture of movement at children of 3-6 years old by means of rhythmic gymnastics”, Slobozhanskii naukovo-sportyvnyi visnyk, No. 3 (47), pp. 80-81, doi.org/10.15391/snsv.2015-3

12. Cecchetti G. (2007), Classical dance a complete manuale of the Cecchetti Method. Gremese editor, $504 \mathrm{p}$.

13. Laws K. (2008), Physics and the Art of Dance: understanding movement. USA: Oxford University Press, 288 pp.

14. Paskevska A. (1988), Ballet: From the first plie to mastery. An eight year course. Princeton Book Company, $531 \mathrm{p}$.

15. Stallibrass A. (1977), The Self-Respecting Child. A Study of Children's Play and Development. Henguin Books, 21 p.

Стаття надійшла до редакції: 09.11.2021 р.

Опубліковано: 23.12.2021 р.

\begin{abstract}
Аннотация. Ольга Рябченко, Эльмира Алиева Эльхан кызы. Определение корреляционной зависимости усвоения базовых элементов художественной гимнастики от использования классического экзерсиса девочек 5-6 лет. Цель: установить корреляционную взаимосвязь базовых элементов художественной гимнастики и специальных упражнений классического экзерсиса. Материал и методы: исследование проводилось на базе КУ “КДЮСШ №1 ХГС» среди девочек 5-6 лет, занимающихся художественной гимнастикой. В эксперименте участвовало 60 юных спортсменок. Для устанавливания корреляционной зависимости были привлечены 3 хореографа и 4 тренера по художественной гимнастике. В связи с тем, что исследование проводилось в группах начальной подготовки второго года обучения, была применена 10-ти балльная шкала оценки. В начале исследования определялось влияние классического экзерсиса на усвоение базовых элементов художественной гимнастики. В конце - устанавливалась корреляция между элементами художественной гимнастики и специальными упражнениями классического экзерсиса. Результаты: в процессе применения специальных упражнений классического экзерсиса (фр. exercice - «упражнение»), то есть изучение элементарных базовых движений устанка - повысился уровень выполнения базовых элементов художественной гимнастики, таких как: скачок «казак» $(t=2,12 ; p<0,05)$, равновесие «вперед» $(t=3,57 ; p<0,001)$, равновесие «аттитюд» $(t=2,68 ; p<0,01)$, поворот «пассе» $(t=2,21 ; p<0,05)$, «колесо» $(t=1,72 ; p>0,05)$. Выводы: в результате исследований определена корреляционная взаимосвязь базовых элементов художественной гимнастики со специальными упражнениями классического экзерсиса.
\end{abstract}

Ключевые слова: художественная гимнастика, базовые элементы, классический экзерсис, корреляция.

Abstract. Olga Riabchenko, Aliiva Elmira Elkhan kyzy. Determination of the correlation dependence of mastering the basic elements of rhythmic gymnastics on the use of the classical exercise by girls 5-6 years old. Purpose: to establish the correlation between the basic elements of rhythmic gymnastics and special exercises of classical exercise. Material and methods: the research was carried out on the basis of the Complex Children's Sports School No. 1, Kyivskyi District (Kharkov) among girls 5-6 years old, going in for rhythmic gymnastics. The experiment involved 60 young athletes. 3 choreographers and 4 rhythmic gymnastics trainers were involved to establish the correlation dependence. Due to the fact that the research was carried out in groups of initial training of the second year of study, a 10-point assessment scale was applied. At the beginning of the study, the influence of classical exercise on the assimilation of the basic elements of rhythmic gymnastics was determined. In the end, a correlation was established between the elements of rhythmic gymnastics and special exercises of the classical exercise. Results: in the process of using special exercises of classical exercise, the level of fulfillment of the basic elements of rhythmic gymnastics increased, such as: jump «Cossack» $(t=2.12$; 


\section{СЛОБОЖАНСЬКИЙ НАУКОВО-СПОРТИВНИЙ ВІСНИК}

$p<0.05)$, balance «forward» $(t=3.57 ; p<0.001)$, balance «attitude» $(t=2.68 ; p<0.01)$, turn «passŭ» $(t=2.21 ; p<0.05)$, «wheel» $(t=$ $1.72 ; p>0.05)$. Conclusions: as a result of the research, the correlation relationship of the basic elements of rhythmic gymnastics with special exercises of classical exercise was determined.

Keywords: rhythmic gymnastics, basic elements, classic exercise, correlation.

\section{References}

1. Artem'eva, G. P., Moshens'ka, T. V. (2018), "The role and significance of choreography in gymnastics and dance sports», Slobozhanskii naukovo-sportyvnyi visnyk, No. 4(66). pp. 32-36, doi:10.15391/snsv.4.005 (in Ukr.).

2. Bazarova, N. P., May, V. P. (2006), «The ABC of classical dance. First Three Years of Study: Study Guide», 3rd edition, Izdatel'stvo «Lan'», 240 p. (in Russ.).

3. Bateeva, N. P., Kizim, P. M., Titkova, I. O., Lutsenko, L. S. (2014), «The use of classical dance tools to improve the technique of performing turns by young gymnasts", Slobozhanskii naukovo-sportyvnyi visnyk, No. 3(41). pp. 19-22, dx.doi.org/10.15391/snsv.3.003 (in Ukr.).

4. Bondarenko, T. M. (2014), Vyhovannia garmoniinoyi osobystosti zasobamy hudozhnioyi gimnastyky [Education of a harmonious personality by means of rhythmic gymnastics]: monografiia; za zagal'noi red. V. M. Klochka; Kharkiv: KhNUMG, 270 p. (in Ukr.).

5. Borsuk, N. V., Mosiakova, I. U., Okushko, T. K (2011), Sportyvna suchasna khoreohrafiya [Modern sports choreography]: kompleksna navchal'na prohrama z pozashkil'noyi osvity. Kyyiv, 64 p. (in Ukr.).

6. Halchenko, L.V., Bessarabova, O.V. \& Pisarkova, O.R. (2017), "On the issue of organizing the training process at the initial stage of girls' preparation in artistic gymnastics», Visnyk Zaporizkoho natsionalnoho universytetu: zbirnyk naukovykh statei. Fizychne vykhovannia ta sport, Zaporizkyi natsionalnyi universytet, Zaporizhzhia, pp. 196-204 (in Ukr.).

7. Goldrich, O. S. (2006), Khoreohrafiya [Choreography], posibnyk z osnov khoreohrafichnoho mystetstva ta kompozytsiyi tantsyu. Vyd. druhe, dopovnene. L'viv: SPOLOM, 172 p. (in Ukr.).

8. Riabchenko, O. V. (2021), «Use of choreography elements in the training process of novice athletes for the successful development of rhythmic gymnastics programs», Slobozhanskii naukovo-sportyvnyi visnyk, No. 3(83). pp. 88-94, doi:10.15391/ snsv. 3.013 (in Ukr.).

9. Sobol', V. A., Panova, E. V. (2019), Klassicheskii tanets: teoriia i metodika prepodavatel'skoi deiatel'nosti [Classical dance: theory and methodology of teaching]: metodicheskoe posobie. Tumen', 64 p. (in Russ.).

10. Rhythmic Gymnastics Judging Rules 2022-2024 y. (2021), FIG Executive Committee, International Gymnastics Federation, 241 p. (in Russ.).

11. Riabchenko, O.V. (2015), «The formation of bases of culture of movement at children of 3-6 years old by means of rhythmic gymnastics», Slobozhanskii naukovo-sportyvnyi visnyk, No. 3 (47), pp. 80-81, doi.org/10.15391/snsv.2015-3 (in Eng.).

12. Cecchetti, G. (2007), Classical dance a complete manuale of the Cecchetti Method. Gremese editor. 504 p. (in Eng.).

13. Laws, K. (2008), Physics and the Art of Dance: understanding movement. USA: Oxford University Press. 288 p. (in Eng.).

14. Paskevska, A. (1988), Ballet: From the first plie to mastery. An eight year course. Princeton Book Company, 531 p. (in Eng.).

15. Stallibrass, A. (1977), The Self-Respecting Child. A Study of Children's Play and Development. Henguin Books, 21 p. (in Eng.).

Received: 09.11.2021.

Published: 23.12.2021.

\section{Відомості про авторів / Information about the Authors}

Рябченко Ольга Вікторівна: Харківська державна академія фізичної культури: вул. Клочківська 99, м. Харків, 61058, Україна. Рябченко Ольга Викторовна: Харьковская государственная академия физической культуры: ул. Клочковская 99, г. Харьков, 61058, Украина.

Olga Riabchenko: Kharkiv State Academy of Physical Culture: 61058, Kharkiv, st. Klochkivska, 99, Ukraine.

ORCID: https://orcid.org/0000-0003-2868-0637

E-mail: riabchenko.ov@gmail.com

Алієва Ельміра Ельхан кизи: Спортивний комплекс Руслан 93 клуб «GymGids», Метро Гара Гараєв, вулиця Алі Веліїв 71/A, Баку, Азербайджан.

Алиева Эльмира Эльхан кызы: Спортивний комплекс Руслан 93 клуб “GymGids», Метро Гара Гараев, улица Али Велиев 71/А, Баку, Азербайджан.

Aliiva Elmira Elkhan kyzy: Sports complex Ruslan 93 club "GymKids", Gara Garayev, Ali Veliyev 71/А, Баку, Азербайджан.

ORCID: https://orcid.org/0000-0002-6307-3472

E-mail: Elmira03@icloud.com 